Visítanos en:

https://journal.poligran.edu.co/index.php/poliantea

\section{Los factores de deserción al tratamiento en pacientes farmacodependientes}

\author{
César Augusto Sierra Varón \\ csierrav@poligran.edu.co \\ Jorge Alberto Velásquez Castrillón \\ jovelasq@poligran.edu.co \\ Institución Universitaria Politécnico \\ Grancolombiano \\ Programa de Psicología Medellín
}

Los procesos académicos de cualquier estudiante deben partir de la premisa fundamental de generar nuevo conocimiento y no de quedarse únicamente en la concepción de pasiva de repetir un conocimiento ya dado por otros autores. Tal aseveración pueda se enmarca en escenarios educativos que se presentan a partir de la investigación. Los constructos teóricos son importantes, pero más importante es la creación de nuevos constructos teóricos que se logran desde la investigación misma. Tal proceso lleva a que la Universidad como Institución Universal invite a que los mismos profesionales en formación se generen preguntas desde problemáticas sociales que detecten, y así se puedan generar posibles alternativas de solución o intervención. El escenario ideal para este tipo de iniciación en investigación está ubicado en los PIF, aquellos proyectos de investigación formativa que le brindan la posibilidad de generar unas competencias básicas en investigación que le permiten plantearse preguntas y llevar a cabo un desarrollo metodológico para llegar a posibles respuestas o hipótesis. En este caso particular, el PIF se lleva a cabo a partir de la observación que se hace de población farmacodependiente y una característica muy dada en la mayoría de ellos, como lo es la poca adherencia al tratamiento, donde la pregunta inicial que enmarca el proyecto es ¿cuáles son las causas que llevan a que los pacientes deserten del tratamiento, buscando aquellos factores causantes desde una mirada psicodinámica de los pacientes con los que se trabajó el proyecto, y así analizar su funcionamiento psíquico respecto al consumo. PIF orientado a partir de la descripción de algunas categorías de análisis que guiaban a encontrar las posibles causas.

\title{
POLIANTEA
}

